\title{
Molecular characterisation of membrane glycoprotein and $5 b$ protein of nephropathogenic infectious bronchitis virus
}

\author{
A. Balasubramaniam, K. Sukumar, P. Suresh and B. Puvarajan \\ Department of Veterinary Microbiology, \\ Veterinary College and Research Institute, Tamil Nadu Veterinary and Animal Sciences University, \\ Namakkal - 637002, Tamil Nadu, India \\ Corresponding author: A. Balasubramaniam, email: balasubramaniam72@gmail.com \\ Received: 19-07-2013, Revised: 20-08-2013, Accepted: 21-08-2013, Published online: 28-09-2013
}

doi: $10.14202 /$ vetworld.2013.857-861

How to cite this article: Balasubramaniam A, Sukumar K, Suresh P and Puvarajan B (2013) Molecular characterisation of membrane glycoprotein and 5b protein of nephropathogenic infectious bronchitis virus, Veterinary World 6(11): 857-861.

\begin{abstract}
Background: Infectious bronchitis virus (IBV) affects the upper respiratory tract and the reproductive tract, and some strains can cause nephritis. Large number of serotypes and genotypes of the virus have been identified and for the most part do not cross-protect. Identifying the genotype or serotype of IBV field strains is empirical for selecting an appropriate candidate to serve as vaccine strain for prevention of infectious bronchitis (IB) disease in chickens. The variant strains of IBV could be circulating among chickens in India and recently nephropathogenic IB was reported. Hence, the present work was aimed to carry out molecular characterization of nephropathogenic IBV isolates obtained from two different geographical locations of south India, involving relatively conserved regions.
\end{abstract}

Materials and Methods: MIBVPCR and NIBVPCR primers were used to amplify partial $\mathrm{M}$ and $\mathrm{N}$ gene after synthesizing cDNA. Isolates Ind/KA/07/1 and Ind/TN/07/2 were subjected to direct sequencing as these two isolates are two different geographical regions and scored better in induction of lesions during pathotyping.

Results: Amino acids of membrane glycoprotein varied on five occasions for the isolate Ind/KA/07/1 when aligned with that of M 41 strain and isolate Ind/TN/07/2. Eight amino acids of both isolates in 5b protein were different from that of M41 strain. Few point mutations, short deletions and insertions were noticed in the amplified genome, based on the membrane protein nucleotide sequence comparison.

Conclusion: Prevalence of IBV strains with few modifications in conserved regions indicated that there was presence of variant IBV in south India.

Keywords: 5 b protein, infectious bronchitis virus, membrane protein, molecular characterization

\section{I ntroduction}

Infectious bronchitis virus (IBV) is a gamma coronavirus that causes a highly contagious disease in chickens. The virus can affect the upper respiratory tract and the reproductive tract. In addition, some strains of IBV are reported to be associated with nephritis as well. Different serotypes and genetic types of the virus have been identified worldwide and the cross-protection elicited between them is very minimum [1]. As IBV exists as multiple different types that do not cross-protect, it is very difficult to control. Attenuated live vaccines are used in broilers and pullets and killed vaccines are typically used in layers and breeders. Effective control involves identification of the virus type causing disease followed by vaccination with an appropriate vaccine against that type [2].

Rapid replication, a high mutation rate, and genome recombination results in extensive genetic diversity and translates into many different types of the virus. The mechanism behind the emergence of new types and variants of the virus is largely unknown. However, there are only a few different types of IBV

Copyright: The authors. This article is an open access article licensed under the terms of the Creative Commons Attribution License (http://creativecommons.org/licenses/by/2.0) which permits unrestricted use, distribution and reproduction in any medium, provided the work is properly cited. vaccines available for use, whereas countless different types and variants of the virus capable of causing disease can be found throughout the world. In addition, some countries only allow vaccination with one or a few vaccine types, making control even more challenging [1].

In India, infectious bronchitis (IB) is one of the important poultry diseases and only vaccines prepared from Massachusetts strain 41 (M41) is being used. The variant strains of IBV that are antigenically different from vaccine strain could be circulating among chickens in India. The Mass (GenBank accession number HM179146) and 793B types were the most common IBV types reported in India since 1991 [3]. Around the year 2000, visceral gout and nephritis was observed in birds less than 2 wk of age and several nephropathogenic and novel strains of IBV were identified in India, despite vaccination [4, 5], China [6, 7, 8], Slovenia [9], Japan [10, 11], Cuba [12], Korea [13], Russia [14] and Brazil [15]. In Southeast Asia, appearance of a new variant of nephropathogenic IBV is also reported $[16,17]$ whereas in Middle East there was variant IBV causing respiratory symptoms [18, 19]. Thus, determining the genotype or serotype of field strains is empirical for selecting an appropriate candidate to act as vaccine strain. 


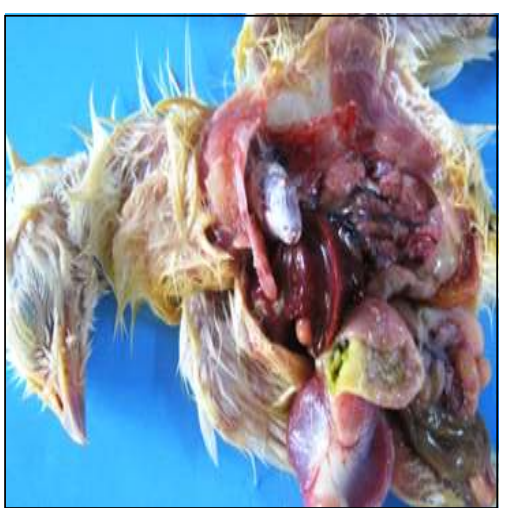

Figure-1. Pale, enlarged kidney and urate deposition in the heart of 10 dayold broiler chick.

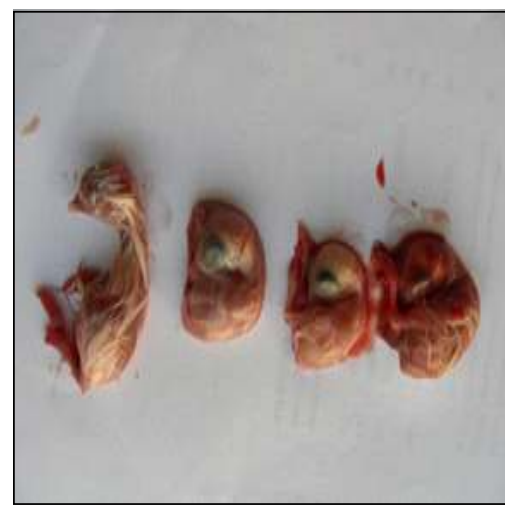

Figure-2. Embryo showing dwarfism and curling of toes inoculated with kidney specimens of broiler chickens after three passages. Control is on left.

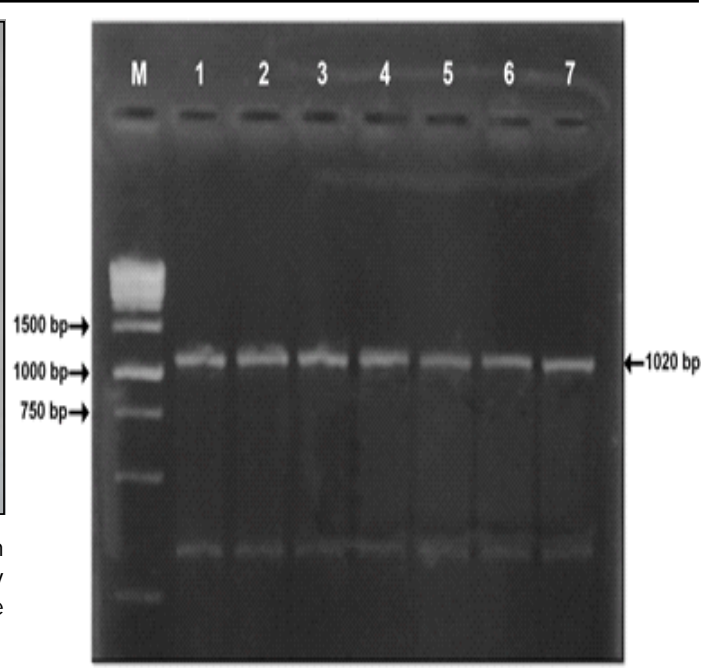

Figure-3. Agarose gel ( 1.5 per cent) electrophoresis of RT-PCR product obtained by amplifying part of $\mathrm{M}$ and $\mathrm{N}$ gene by using the primers MIBVPCR and NIBVPCR of field isolates and vaccine strain H120; Lane M: 500 bp marker; Lane 1 to 6: Field isolates; Lane 7: Vaccine strain H120

Different serotypes thought to be generated by nucleotide point mutations, insertions, deletions or recombination of $\mathrm{S} 1$ and other genes could be circulating among chickens in India. Hence, the present work was aimed at the molecular characterization of nephropathogenic IBV isolates obtained from two different geographical locations of south India, involving relatively conserved regions.

\section{Materials and Methods}

Virus isolation: On post mortem examination, kidney showing paleness and enlargement with urate deposits in the ureter from the commercial broiler chickens reared in south India were collected and transported in $50 \%$ glycerol saline or on ice to the laboratory. The samples were subjected for isolation in embryonated chicken eggs (ECE) of specific pathogen free (SPF) origin.

Reverse transcriptase PCR (RT-PCR): Allantoic fluid samples collected from ECE showing IBV-characteristic embryo lesions were subjected for amplification of partial M and $\mathrm{N}$ genes of IBV.

Viral RNA extraction: Viral RNA extraction was carried out using TRIsol Reagent (Genei, Bangaluru, India) following instructions given by manufacturer.

Synthesis of cDNA: cDNA was synthesized by using Revert Aid First Strand Synthesis ${ }^{\circledR}$ kit (Fermentas, USA) as per the recommendations of the manufacturer. The reaction mix for cDNA synthesis was carried out as follows:

$11 \mu \mathrm{l}$ of RNA and $1 \mu \mathrm{l}$ of specific forward or reverse primer were heated at $70^{\circ} \mathrm{C}$ for 5 min and snapchilled on ice for $1 \mathrm{~min}$. Then the following were added: $4 \mu$ l of 5 X RT-PCR buffer $(250 \mathrm{mM}$ of Tris $\mathrm{HCl}$, $250 \mathrm{mM} \mathrm{KCL}, 50 \mathrm{mM}$ of DTT), $2 \mu 1$ of dNTP $(10 \mathrm{mM}$ each) and $1 \mu$ of RNAse inhibitor (20U). The contents were mixed gently and kept at $25^{\circ} \mathrm{C}$ for $5 \mathrm{~min}$. $200 \mathrm{U}$ of MmLV reverse transcriptase $(1 \mu \mathrm{l})$ was added and mixed. This reaction mixture was kept in a thermal cycler with a cyclic condition programme of $25^{\circ} \mathrm{C}$ for $10 \mathrm{~min}, 42^{\circ} \mathrm{C}$ for $60 \mathrm{~min}$ and $70^{\circ} \mathrm{C}$ for $10 \mathrm{~min}$. The synthesized cDNA was used either immediately for PCR or stored at $-20^{\circ} \mathrm{C}$.

Primers for amplification: Previously published primers for PCR amplification of partial $\mathrm{M}$ and $\mathrm{Ngenes}$ of IBV [20] were utilized and the sequences are as follows;

Forward: 5'- TAA GCT TTC AGT GGC TTG CTA AGT GTG AAC C-3' (MIBVPCR) and Reverse: 5'-TGG ATC CAC CGC TAC CTT CAA ACT TGG GCG G-3' (NIBVPCR).

Polymerase chain reaction: PCR reaction mix contained $3.0 \mu \mathrm{l}$ of cDNA, 20 picomoles of MIBVPCR, 20 picomoles of NIBVPCR, $2.5 \mu 1$ of 10X PCR buffer, $1.0 \mu \mathrm{l}$ of dNTP (10 mM each), $1.0 \mu \mathrm{l}$ of Taq DNA polymerase $(5 \mathrm{U} / \mu \mathrm{l})$ and nuclease free water to make upto $25 \mu$ l. Cycling condition followed was as follows : initial denaturation $94^{\circ} \mathrm{C}$ for $3 \mathrm{~min} ; 30$ cycles of $94{ }^{\circ} \mathrm{C}$ for $1 \mathrm{~min} ; 37^{\circ} \mathrm{C}$ for $2 \mathrm{~min} ; 74^{\circ} \mathrm{C}$ for $5 \mathrm{~min}$, followed by final extension of $74^{\circ} \mathrm{C}$ for $10 \mathrm{~min}$.

Sequencing: Isolates Ind/KA/07/1 and Ind/TN/07/2 were subjected to direct sequencing using MIBVPCR and NIBVPCR primers. For these two isolates, a bulk PCR $(50 \mu \mathrm{l})$ was carried out and PCR products in agarose gel were purified using Purefast ${ }^{\circledR}$ gel extraction kit (Helini Biomolecules, Chennai, India) and used for sequencing. Sequencing with MIBVPCR and NIBVPCR primers was done in automated sequencer using $\mathrm{AB}$ prism 96 capillary systems by using BigDyesTN kit (Applied Biosystems, USA). The complete sequence data for each sample was constructed by adding the complementary sequence with the actual data of forward sequencing. The nucleotide sequence reported in this article has been submitted to GenBank and published (accession isolates Ind/KA/07/1 and Ind/TN/07/2 respectively). numbers JF730308 and JF730309 for 5b protein of the 


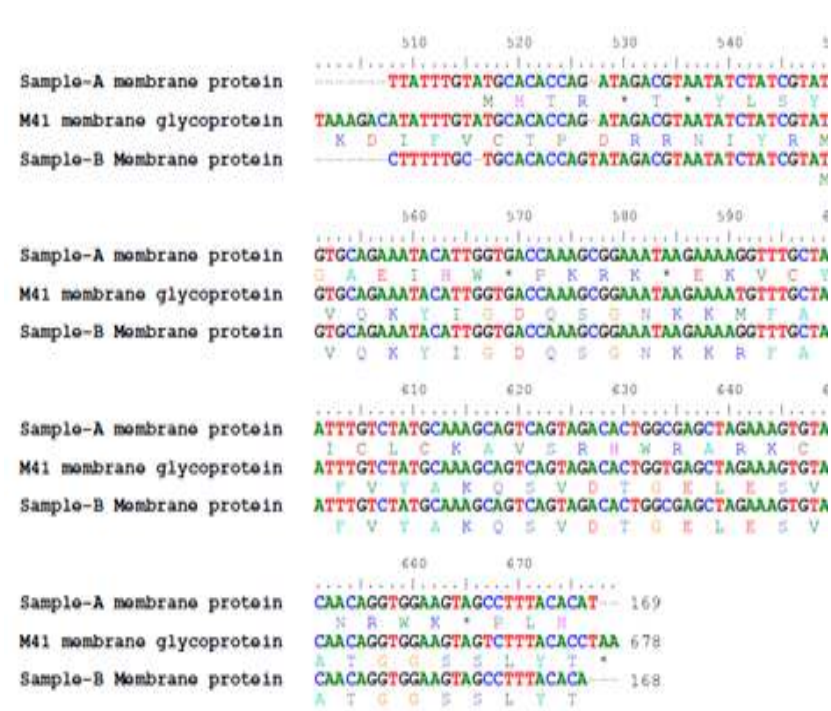

Figure-4. Multiple sequence alignment of both nucleotides and amino acids (in single letter code) for a total of $169 \mathrm{bp}$ of $\mathrm{M}$ gene of isolates Ind/KA/07/1 (Sample A) and Ind/TN/07/2 (Sample B) along with that of M 41 strain.

Nucleotide alignment: The nucleotide sequence coding for partial $\mathrm{M}$ and $\mathrm{N}$ proteins of IBV isolates were aligned by ClustalW method using MegAlign programme of Lasergene software (DNA Star Inc., USA).

\section{Results}

At the age of one to three weeks, there was outbreak of visceral gout in which there was 10 to 20 per cent mortality. On postmortem, all dead broilers chicks showed deposition of urates in visceral organs and kidney was pale and enlarged (Figure-1). The age of broiler chicken from which samples were collected, was 8 to 15 days and they were not vaccinated with IB vaccine. However, their parent flocks were vaccinated against IB. Nine to eleven day-old ECE of SPF origin were inoculated with $200 \mu \mathrm{l}$ of the samples through allantoic cavity and incubated for seven to 8 days at $37^{\circ} \mathrm{C}$ in order to see the typical lesions such as embryo dwarfism and curling of toes. Such lesions were observed in 11 and two from broiler and layer chickens respectively between third and fourth passage levels (Figure-2).

RT-PCR for allantoic fluid from IBV positive samples was carried out for the amplification of $\mathrm{M}$ and $\mathrm{N}$ genes and the $1020 \mathrm{bp}$ product of field isolates and vaccine strain H120 (Figure-3).

Multiple sequence alignment of both nucleotide and amino acid sequence for a total of $169 \mathrm{bp}$ pertaining to the coding sequence alone in the membrane glycoprotein region of both isolates along with reference strain M41 are shown in Figure 4. Amino acid variations from that of M41 are indicated by star without the letter. Amino acids of membrane glycoprotein when aligned with that of M 41 strain and isolate Ind/TN/07/2 varied on five occasions for the isolate Ind/KA/07/1. Nucleotide at position 166 for both isolates varied from that of M41 strain although

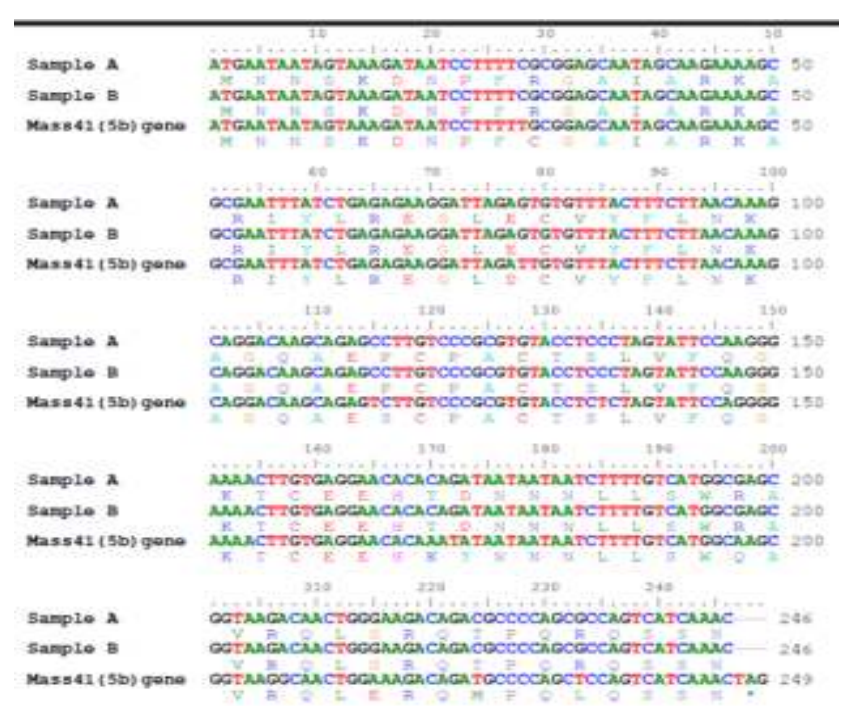

Figure-5. Multiple sequence alignment of both nucleotides and amino acids (in single letter code) for a total of $249 \mathrm{bp}$ of $5 \mathrm{~b}$ protein coding gene of isolates Ind/KA/07/1 (Sample A) and Ind/TN/07/2 (Sample B) along with that of M 41 strain.

there is no change in amino acid coded.

Multiple sequence alignment of both nucleotide and amino acid sequence for a total of $249 \mathrm{bp}$ pertaining to $5 \mathrm{~b}$ protein gene of both isolates along with reference strain M41 are shown (Figure-5). Eight amino acids of both isolates in $5 \mathrm{~b}$ protein were different from that of M41 strain. Nucleotide at positions 27, 76, $116,170,197,216,225$ and 234 varied from that of M41 strain that led to coding for different amino acids. The amino acid arginine was predominant for both the isolates in substituting amino acids leucine, glutamine and cysteine which are coded in M41 strain.

\section{Discussion}

Despite vaccination with Massachusetts (M41) strain of IBV, there was outbreak of visceral gout in which there was 10 to 20 per cent mortality during first month of life in broilers due to nephropathogenic strains of IBV. These findings were in accordance with the reports made by other authors $[4,5]$.

Primers MIBVPCR and NIBVPCR were able to anneal to genome of the field isolates indicating there are no genetic modification such as single nucleotide polymorphism in the annealing regions of these primers. In membrane protein amino acid sequence, isolate Ind/KA/07/1 differed from M41 strain which led to the conclusion that there is prevalence of variant strain in this region. Although it may be ideal to sequence the complete genome or entire $\mathrm{S} 1$ gene of the isolates to assign the genotype, many workers resorted to sequencing of hypervariable regions alone [21, 22]. Genotyping is an excellent tool for epidemiological studies and is a convenient, practical tool for typing that can be used best as a means of screening to select potentially important strains [23]. For correct comparisons, the whole genome or more conserved regions are to be compared as any changes in this region will clearly bring out the difference $[24,25]$. The suggestions made by these authors are considered 
for this study.

Isolates Ind/TN/07/2 and Ind/KA/07/1 were chosen for sequencing owing to their better lesion score than other isolates in pathotyping trials involving all the isolates in broiler chickens and also these two isolates from two different geographical regions (data not shown). Changes in amino acid sequence may influence cellular tropism. The variation in $\mathrm{N}$ glycosylation sites may affect survival, transmission of the virus, the interaction with receptors and render a virus more susceptible to host innate immune system. Hence these changes affect the recognition by antibody, the virus replication and infectivity. The small changes can lead to disturbance in folding and conformation of the molecule [26]. The replacement of arginine with other amino acid may hinder the neutralization activity of antibodies. This finding is in agreement with the finding of other research group [26] which analysed S1 glycoprotein. The changes in the amino acids in the $5 \mathrm{~b}$ protein of membrane glycoprotein of isolates Ind/TN/07/2 and Ind/KA/07/1 showed variation in $\mathrm{N}$-glycosylation and phosphorylation sites, as compared to M41 strain.

Few point mutations, short deletions and insertions were noticed in the amplified genome, based on the membrane protein nucleotide sequence comparison. Similarly, changes in S1 and M genes are reported [27] whereas variations were found in $\mathrm{N}$ gene which is in agreement with the findings of this study (data not shown). On the contrary, $\mathrm{N}$ gene of IBV was sufficiently conserved to detect all the IBV strains [28].

The isolate Ind/TN/07/2 was found to be more closely related to M41 strain whereas the isolate Ind/KA/07/1 showed more variation in multiple sequence alignment. This finding suggests that there is rampant variation among the isolates from different variation which substantiates IBV is prone for mutation owing to its poor proof-reading ability during replication $[6,7]$. It is certain that new variants could emerge due to exertion of prolonged immunological pressure. The smaller degree of variation in the conserved regions indicates that the isolates emerged under selective immunological pressure. This observation finds correlation with that of another research group [29]. Partial protection conferred by M41 strain against isolates of the study in protectotyping trial proved that there is minimal crossprotection (data not shown). Naturally occurring recombination between distant strains of IBV was also reported [30] which substantiates the finding of the study.

\section{Conclusion}

RT-PCR for partial $\mathrm{M}$ and $\mathrm{N}$ genes was carried out to amplify 1020 bp product for field isolates of infectious bronchitis virus using MIBVPCR and NIBVPCR primers. Direct sequencing of amplified products of the isolates Ind/KA/07/1 and Ind/TN/07/2 was carried out. Analysis of multiple sequence alignment for membrane glycoprotein (169 bp) with reference strain M41 revealed variations. The isolate Ind/KA/07/1 showed more variation with reference strain M41 in the alignment than Ind/TN/07/2. Prevalence of IBV strains with few modifications in conserved regions indicates that there is presence of variant IBV in south India.

\section{Authors' contributions}

$\mathrm{AB}$ conceived the work and executed the plan of work desired by other authors. KS carried out molecular analysis. PS and BP contributed in the discussion. All authors contributed in drafting and revision of manuscript. All authors read and approved the final manuscript.

\section{Acknowledgements}

The authors are thankful to the Tamil Nadu Veterinary and Animal Sciences University and the Dean, Veterinary College and Research Institute, Namakkal - 637002, India for providing the fund and facilities.

\section{Competing interests}

The authors declare that they have no competing interests.

\section{References}

1. Jackwood, M.W. (2012) Review of infectious bronchitis virus around the world. Avian Dis., 56:634-641.

2. Cavanagh, D., and J. Gelb Jr. Infectious bronchitis. (2008) In: Diseases of poultry, 12th ed. Saif, Y.M., Fadly, A.M., Glisson, J.R., McDougald, L.R., Nolan, L.K. and Swayne, D.E. eds. Blackwell Publishing, Ames, IA. pp. 117-135.

3. Elankumaran, S., C. Balachandran, N. D. Chandran, P. Roy, A. Albert, and R. Manickam. (1999) Serological evidence for a 793B related avian infectious bronchitis virus in India. Vet. Rec. 144:299-300.

4. Bayry, J., Goudar, M.S., Nighot, P.K., Kshirsagar, S.G., Ladman, B.S., Gelb Jr., J., Ghalsasi, G.R. and Kolte, G.N. (2005) Emergence of a nephropathogenic avian infectious bronchitis virus with a novel genotype in India. J. Clin. Microbiol., 43:916-918.

5. Singh, F., Shakya, S. and Rawat, N. (2009) An outbreak of nephropathogenic avian infectious bronchitis in broiler flocks of Chhattisgarh region. Indian Journal of Poultry Science 44:379-381.

6. Bing G.X., Liu, X, Pu, J., Liu, Q.F., Wu, Q.M. and Liu, J.H. (2007) Different genotypes of nephropathogenic infectious bronchitis virus co-circulating in chicken population in China. Virus Genes 35: 333-337.

7. Han, Z., Sun, C. Yan, B., Zhang, X., Wang, Y., Li, C., Zhang, Q., Ma, Y., Shao, Y. Liu, Q., Kong, X. and Liu, S. (2011) A 15-year analysis of molecular epidemiology of avian infectious bronchitis coronavirus in China. Infect. Genet. Evol., 11:190-200.

8. Ji, J., Xie, J., Chen, F., Shu, D., Zuo, K., Xue, C., Qin, J., Li, H., Bi, Y., Ma, J. and Xie, Q. (2011) Phylogenetic distribution and predominant genotype of the avian infectious bronchitis virus in China during 2008-2009. Virol. J., 8:184

9. Krapez, U., Slavec, B. and Rojs, O.Z. (2011) Circulation of infectious bronchitis virus strains from Italy 02 and $\mathrm{QX}$ genotypes in Slovenia between 2007 and 2009. Avian Dis., 55:155-161.

10. Ariyoshi, R., Kawai, T., Honda, T. and Tokiyoshi, S. (2010) Classification of IBV S1 genotypes by direct reverse transcriptase-polymerase chain reaction (RT-PCR) and 
relationship between serotypes and genotypes of strains isolated between 1998 and 2008 in Japan. J. Vet. Med. Sci., 72:687-692.

11. Mase, M., Kawanishi, N., Ootani, Y., Murayama, K., Karino, A., Inoue, T. and Kawakami, J. (2010) A novel genotype of avian infectious bronchitis virus isolated in Japan in 2009. $J$. Vet.Med. Sci., 72:1265-1268.

12. Acevedo, A.M., Diaz de Arce, H., Brandao, P.E., Colas, M., Oliveira, S. and Perez, L.J. (2012) First evidence of the emergence of novel putative infectious bronchitis virus genotypes in Cuba. Res. Vet. Sci., 93:1046-1049.

13. Lim, T.H., Lee, H.J., Lee, D.H., Lee, Y.N., Park, J.K., Youn, H.N., Kim, M.S., Lee, J.B. Park, S.Y., Choi, S. and Song, C.S. (2011) An emerging recombinant cluster of nephropathogenic strains of avian infectious bronchitis virus in Korea. Infect. Genet. Evol., 11:678-685.

14. Ovchinnikova, E.V., Bochkov, Y.A., Shcherbakova, L.O., Nikonova, Z.B., Zinyakov, N.G., Elatkin, N.P., Mudrak, N.S., Borisov, A.V. and Drygin, V.V. (2011) Molecular characterization of infectious bronchitis virus isolates from Russia and neighbouring countries: identification of intertypic recombination in the S1 gene. Avian Pathol., 40:507-514.

15. Fraga, A.P., Balestrin, E., Ikuta, N., Fonseca A.S.K., Spilki, F.R., Canal, C.W. and Lunge, V.R. (2013) Emergence of a new genotype of avian infectious bronchitis virus in Brazil. Avian Dis., 57:225-232.

16. Kang, S.C., Eun, K.L., Woo, J.J., Mi, J.P. Jin, W.K. and Jun, H.K. (2009) Pathogenicity and antigenicity of a new variant of Korean nephropathogenic infectious bronchitis virus. $J$. Vet. Sci., 10: 357-359.

17. Pohuang, T. and Sasipreeyajan, J. (2012) The pathogenesis of a new variant genotype and QX like infectious bronchitis virus isolated from chickens in Thailand. Thai J. Vet. Med., 42: 51-57.

18. Ababneh, M., Dalab, A.E., Alsaad, S. and Al-zghoul, M. (2012) Presence of infectious bronchitis virus strain CK/CH/ LDL/97I in the Middle East. Vet. Sci., doi:10.5402/2012/ 201721.

19. Mahmood, Z.H., Sleman, R.R. and Uthman, A.U. (2011) Isolation and molecular characterization of Sul/01/09 avian infectious bronchitis virus, indicates the emergence of a new genotype in the Middle East. Vet. Microbiol., 150:21-27.

20. Andreasen, J. R., Jackwood, M. R. and Hilt, D.A. (1991) Polymerase chain reaction amplification of the genome of infectious bronchitis virus. Avian Dis., 35: 216-220.

21. Wang, C.H. and Huang Y.C. (2000) Relationship between serotypes and genotypes based on the hypervariable region of the SI gene of infectious bronchitis virus. Arch. Virol., 145: 291-300.

22. Jones, R.C., Worthington, K.J., Capua, I.and Naylor, C.J. (2005) Efficacy of live infectious bronchitis vaccines against novel European genotype, Italy 02. Vet. Rec., 156: 6-647.

23. de Wit, J. J., J. K. Cook, and H. M. van der Heijden. (2011) Infectious bronchitis virus variants: a review of the history, current situation and control measures. Avian Pathol., 40: 223-235.

24. Yu, L., Jiang, Y. Low, S. Wang, Z. Nam, S.J. Liu W.L. and Kwang, J. (2001) Characterization of three infectious bronchitis virus isolates from China associated with proventriculus in vaccinated chickens. Avian Dis., 45: 416 424.

25. Farsang, A., Ros, C, Renstrom, H. M. Baule, C. Soos, Y. and Selak, S. (2002) Molecular epizootiology of infectious bronchitis virus in Sweden indicating the involvement of vaccine strain. Avian Pathol., 31:229-236.

26. Abro, S.H., Renstrom, L.H., Ullman, K., Isaksson, M., Zohari, S., Jansson, D.S., Belak, S. and Baule, C. (2011) Emergence of novel strains of avian infectious bronchitis virus in Sweden. Vet. Microbiol., 155:237-246.

27. Zulperi, Z.M., Omar, A. R. and Arshad, S. S. (2009) Sequence and Phylogenetic analysis of S1, S2, M, and N genes of infectious bronchitis virus isolates from Malaysia. Virus Genes, 38: 383-391.

28. Zwaagstra, K.A., Van Zeijst, B.A.M. and Kusters, J.G. (1992) Rapid detection and identification of avian infectious bronchitis virus. J. Clini. Microbiol., 30: 79 - 84.

29. Li, H. and Yang, H. (2001) Sequence analysis of nephropathogenic infectious bronchitis virus strains of the Massachusetts genotype in Beijing. Avian Pathol., 30: 535 -541.

30. Mardani, K., Noormohammadi, A.H., Ignjatovic, J. and Browning, G.F. (2010) Naturally occurring recombination between distant strains of infectious bronchitis virus. Arch. Virol., 155:1581-1586.

$* * * * * * * *$ 